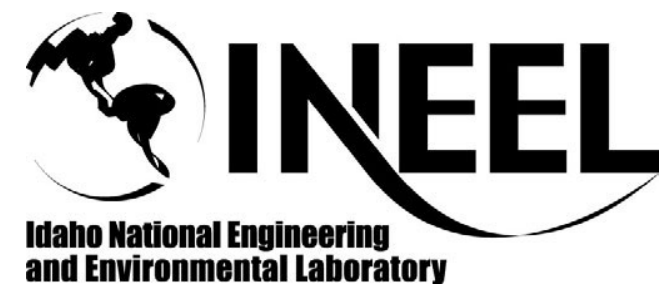

\author{
INEEL/CON-04-02397 \\ PREPRINT \\ Idaho Explosives Detection System
}

Edward L. Reber

Larry G. Blackwood

Andrew J. Edwards

J. Keith Jewell

Kenneth W. Rohde

Edward H. Seabury

Jeffery B. Klinger

October 10-15, 2004

International Conference On The Application of Accelerators In Research And Industry

This is a preprint of a paper intended for publication in a journal or proceedings. Since changes may be made before publication, this preprint should not be cited or reproduced without permission of the author.

This document was prepared as an account of work sponsored by an agency of the United States Government. Neither the United States Government nor any agency thereof, or any of their employees, makes any warranty, expressed or implied, or assumes any legal liability or responsibility for any third party's use, or the results of such use, of any information, apparatus, product or process disclosed in this report, or represents that its use by such third party would not infringe privately owned rights. The views expressed in this paper are not necessarily those of the U.S. Government or the sponsoring agency. 


\title{
Idaho Explosives Detection System
}

\author{
Edward L. Reber ${ }^{*}$, Larry G. Blackwood, Andrew J. Edwards, J. Keith Jewell, \\ Kenneth W. Rohde, Edward H. Seabury, Jeffery B. Klinger \\ Idaho National Laboratory \\ 2525 N. Freemont Ave., Idaho Falls, ID 83415-2114
}

\begin{abstract}
The Idaho Explosives Detection System (IEDS) was developed at the Idaho National Laboratory (INL) to respond to threats imposed by delivery trucks carrying explosives into military bases. A full-scale prototype system has been built and is currently undergoing testing. The system consists of two racks, one on each side of a subject vehicle. Each rack includes a neutron generator and an array of $\mathrm{NaI}$ detectors. The two neutron generators are pulsed and synchronized. A laptop computer controls the entire system. The control software is easily operable by minimally trained staff. The system was developed to detect explosives in a medium size truck within a 5-minute measurement time. System performance was successfully demonstrated with explosives at the INL in June 2004 and at Andrews Air Force Base in July 2004.
\end{abstract}

*Corresponding author - Edward L Reber, 2525 N. Freemont Ave., MS 2114, Idaho Falls, ID 83415-2114, Phone (208) 526-1410, FAX (208) 526-9267, Email Edward.Reber@inl.gov

This paper is to be published in 2005 in Nuclear Instruments \& Methods in Physics Research as Proceedings of the International Conference on the Application of Accelerators in Research and Industry, October 10-15, 2004, Fort Worth, Texas. 


\section{Introduction}

The Idaho Explosives Detection System was developed over the past two years to fill the need for a large vehicle explosive detection system. Currently, vehicles entering facilities such as military bases and embassies are checked for explosives by physical search, x-ray, vapor detection, or K-9 units. The IEDS is a non-destructive, non-intrusive, and non-contact system. In other words, the IEDS can interrogate a vehicle without opening it up and risking the life of the inspector. After a year of design and component testing, a fullscale operational prototype system was built. The IEDS was successfully demonstrated in June 2004 at the INL and in July 2004 at Andrews Air Force Base where explosives were detected within 5 minutes. At both demonstrations it was also shown that the system correctly identified a vehicle containing no explosives.

The key requirements specified for the system were: detect explosives in a mid-size delivery truck; detect explosives concealed within a vehicle; measurement and analysis time of 5 minutes or less; use commercial off the shelf (COTS) components as much as possible; minimal training needed to operate; operate safely; non-destructive, non-intrusive, and non-contact system; go/no go reporting; detect explosives such as ammonium nitrate and fuel oil (ANFO), pentaerythrite tetranitrate (PETN), composition $4(\mathrm{C} 4)$, trinitrotoluene (TNT), etc. The IEDS has met or exceeded all these requirements.

\section{Description}

The IEDS uses two pulsed D-T neutron generators $[1,2]$ to interrogate a vehicle. The high-energy neutrons penetrate the subject vehicle where they interact with the explosive and inelastically scatter off various elements until they eventually thermalize and are captured. These interactions release signature gamma rays from the explosive, which are measured by a large array of NaI detectors.
Explosives have been shown [3] to be chemically distinct from innocuous materials. The acquired gamma ray spectra are analyzed to identify the major elemental components of the explosives. An alarm condition exists when the system detects these elements in certain minimum quantities.

The entire system is controlled from a laptop computer. INL developed software is used to control the neutron generator operation, monitor the health of the system, monitor the interrogation progress, process and analyze the data, and give a go/no-go result. The inspection of a subject vehicle begins with the vehicle driving into position between the two identical IEDS racks. Once the driver exits the vehicle and the radiation exclusion zone, the system racks are moved close to the vehicle. This is referred to as pinching the vehicle. The 2 mrem per hour radiation exclusion zone is approximately 90 feet long by 60 feet wide. The IEDS operator is located outside this zone up to 4000 feet away. Each of the system's racks contains a neutron generator, an array of 5-inch diameter by 5 -inch deep sodium iodide $(5 \times 5 \mathrm{NaI})$ detectors and shielding. Once the vehicle is pinched the neutron generators are turned on and warmed up for approximately 85 seconds. After warm-up the neutron interrogation begins.

Each $\mathrm{NaI}$ detector is connected to a digiBASE [4], which contains an integrated bias supply, preamplifier and digital multichannel analyzer. All the digiBASEs are connected to the control laptop computer by USB cables through USB hubs, which provide power to the bases. The only other connection on the digiBASE is a gating input. Data are collected and stored by the digiBASEs during the interrogation. Periodically during the interrogation the stored data are read from all the digiBASEs at a rate of $12 \mathrm{Mbps}$ (USB 1.1). Because the data are read in spectrum form from the 
digiBASEs, the speed of the USB is not crucial.

When the interrogation is complete a spectrum is read from each detector. The spectra are then automatically calibrated. The automatic calibration is accomplished by using always-present gamma rays including Hydrogen at $2.2 \mathrm{MeV}$. Spectra with calibration coefficients outside preset ranges are rejected and not analyzed. After the initial individual calibration occurs spectra are shifted to one common calibration, which allows the spectra to be added together. Finally, the spectra are analyzed for signature gamma rays using INL developed algorithms. Depending on the results of the analysis the operator is alerted with an "All Clear" message indicating no explosives detected or a "Suspect Cargo" message indicating that explosives were detected. At an administrator-defined interval during the interrogation, preliminary results can be given. The entire interrogation and analysis time, including the neutron generator warmup time, is less than 300 seconds ( 5 minutes).

The IEDS includes a feature that allows the operator to change the sensitivity of the system in response to changes in facility alert status. The desired sensitivity is selected by choosing one of four threat levels (Alpha, Bravo, Charlie, or Delta). Each level corresponds to a different balance of count time, false positive and false negative rates.

All the current demonstrations were preformed with a "clutter free" truck, meaning no additional materials were present in the trucks except for some miscellaneous storage boxes and equipment. Currently there are plans for additional testing to measure trucks filled with various materials.

\section{Signal-To-Noise Ratio}

One of the design considerations for the system was to maximize the signal-to-noise ratio. To maximize the signal, highly efficient $5 \times 5 \mathrm{NaI}$ detectors with factory quoted resolutions ranging from $6.5 \%$ to $7.4 \%$ using a ${ }^{137} \mathrm{Cs}$ source were chosen. A disadvantage of the NaI detector is that their gain changes with neutron activation. This is counter-acted by the gain stabilizer built into the digiBASE and by our automatic calibration algorithm. Gain changes of the $\mathrm{NaI}$ detectors due to temperature are much less significant than due to the neutron activation and are also minimized because the material surrounding the detectors reduces the temperature fluctuations.

The detectors are distributed over the length of a typical mid-size delivery truck. This arrangement means there will be a detector close to the explosives no matter where they are located in the subject vehicle. Signal strength can be further improved by raising the flux of neutrons interrogating the vehicle. Adding more neutron generators or using higher flux neutron generators can achieve this. Both of these options are costly. The addition of a neutron generator would raise the cost of a system significantly and running a neutron generator at a higher neutron flux output would reduce the lifetime of the neutron generator tube, increasing maintenance costs.

Another way of increasing the signal-tonoise ratio is to reduce the background seen by the detectors. The shielding configuration blocks the detectors from neutrons from the generators as well as unwanted gamma rays produced from surrounding materials. This shielding reduces the neutron flux on the detectors as well as the radiation footprint of the system.

\section{Graphical User Interface}

The IEDS has two levels of users, the operator and the administrator. The operator is allowed to check the status/health of the system and, of course, run the system. The administrator sets up the system originally and has control over all preferences and settings. One of the requirements for the 
IEDS was to make the system easy to operate. Figure 1 shows the main graphical user interface (GUI), which the operator would see after the system is first powered on. The GUI was intentionally simplified allowing the operator to quickly determine the status of the system. The GUI indicates the threat level, progress of the interrogation, status, and the two neutron generators' voltage and current. The status button displays the health of the system; green indicates that the control computer is communicating with all detectors and generators; yellow indicates loss of connection with at least one detector; and red indicates loss of communication with at least a threshold number of detectors. The administrator of the system sets this threshold. The system has the ability to operate even with the loss of detectors below the threshold. The results window is located at the center bottom of the GUI. This will display one of the following: Idle, Interrogating, Processing, All Clear, or Suspect Cargo. If at anytime the control computer looses communication with the neutron generators for more than a few seconds the neutron generators will shut down. Also, as a fail safe, if the system takes longer than is required for an interrogation the system will shutdown.

\section{Summary}

INL has built a full-scale prototype explosive detection system that will detect explosives in a mid-size truck within 5 minutes. IEDS was successfully demonstrated in June 2004 at the INL where it measured explosives (a mixture of PETN and C4). IEDS was also successfully demonstrated in July 2004 at Andrews Air Force Base (Figure 2) where it measured
ANFO within 5 minutes. At both demonstrations it was also shown that the system correctly identified a truck containing no explosives.

\section{Future}

During the next year IEDS will be optimized to increase the detection capabilities while reducing the false positive rate. IEDS will then undergo extensive verification and validation measurements. Also a new environmentally protected rack design will be developed and the entire system will be licensed to a future manufacturer.

\section{Acknowledgments}

We wish to acknowledge the Applied Physics Institute at Western Kentucky University for their part in the development of this system. This work was funded by the DoD Physical Security Equipment Action Group managed by the Electronic Systems Center at Hanscom Air Force Base. This work was supported in part by the U.S. Department of Energy under BBWI Contract DE-AC07-99ID13727.

\section{References}

[1] - P.C. Womble, G. Vourvopoulos, J. Paschal, I. Novikov, G. Chen, Nuclear Instruments \& Methods in Physics Research A 505, 2003, p. 470-473.

[2] - T. Gozani, M. Elsalim, D. Strellis, D. Brown, Nuclear Instruments \& Methods in Physics Research A 505, 2003, p. 486-489.

[3] - G. Vourvopoulos, Chemistry and Industry, 18 April 1994, p. 297-300.

[4] - Ortec website - http://www.orteconline.com/pdf/digibase.pdf 


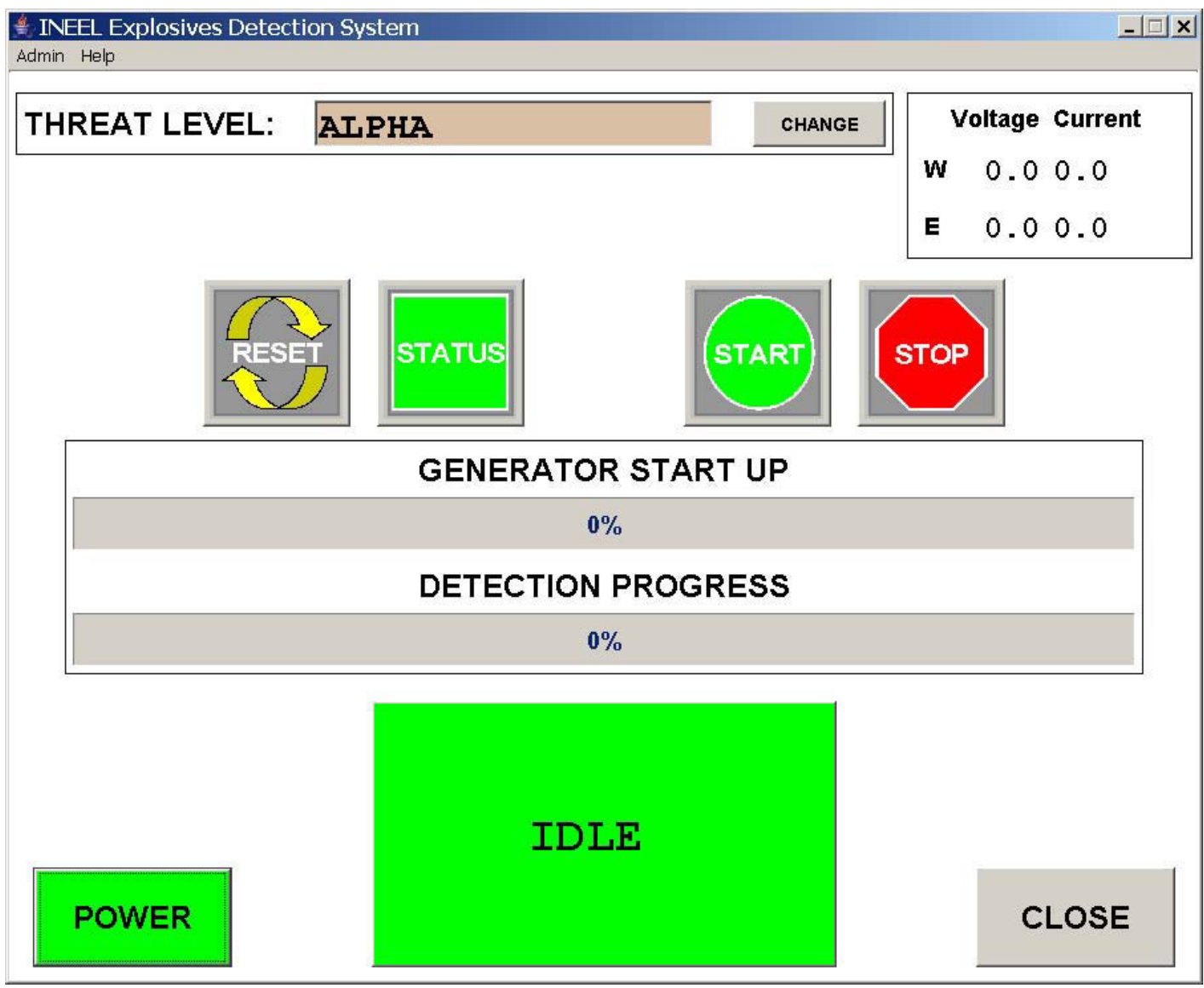

Figure 1 - Graphical User Interface of the IEDS system control screen.

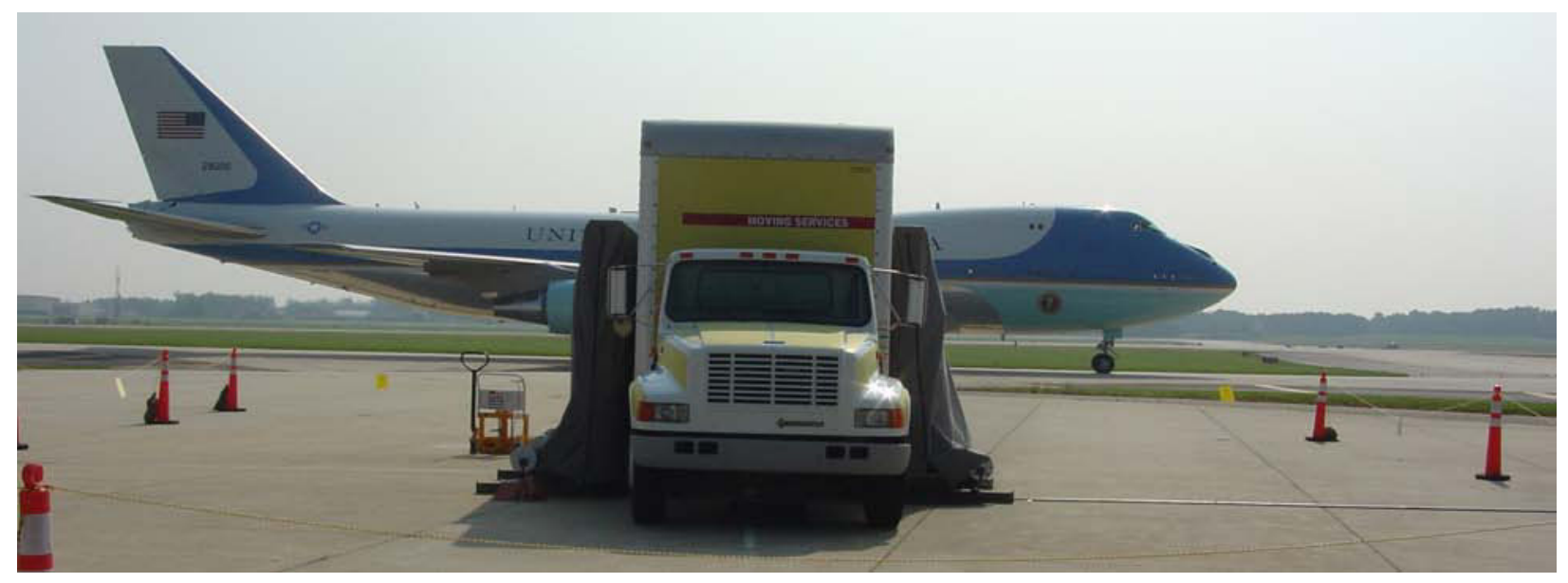

Figure 2 - Andrews Air Force Base demonstration (July 2004) of the IEDS. In the foreground, a truck containing ANFO is being interrogated, while the Air Force One plane taxis by in the background. 